\title{
ENERGY EFFICIENCY IN NORWEGIAN NEWS MEDIA:
}

\author{
A Glitch in the Discourse-as-Usual \\ by Jens Petter Johansen, Jens Røyrvik and Håkon Fyhn
}

This article investigates how energy efficiency features in Norwegian news media discourse. Based on an analysis of 309 news articles, we explore the objectification of energy efficiency and its rhetorical connections to energy savings and reductions. Energy efficiency is surrounded by positive overtones and used flexibly to include different meanings as well as effects. As a discursive object, the term wields significant rhetorical and legitimizing power, producing consensus across conflicting narratives and controversies in what we call the "discourse-as-usual". We argue that energy efficiency shares characteristics with boundary objects, conveying an interpretive flexibility to bridge otherwise incommensurable perspectives on the need to decrease or increase absolute energy consumption. However, there are a few instances where controversy turns toward energy efficiency itself, revealing different views on absolute limits to energy consumption. By scrutinizing one of these glitches in consensus, we examine the normal through the anomaly to pinpoint the moral prerogative of energy efficiency in the discourse-as-usual. By black-boxing the complex relationship between efficiency and reductions, the term allows for avoiding the question of absolute limits to energy consumption in news media debates. Rather than translate between climate change and economic stability and growth narratives, we assert that energy efficiency as a discursive object conceals opposition between them. We discuss this concealment as a form of system dependency, as it is by black-boxing the effects of energy efficiency that it can unite adversaries and ensure ongoing activity.

Keywords: Authors: 


\section{Introduction}

Energy efficiency has become a key political strategy to reduce carbon emissions in Norway and is promoted as a solution with multiple benefits, such as mitigating climate change, boosting local economies, increasing economic competitiveness, and reducing dependency on energy imports (Enova, 2020; European Commission, 2016). The lack of controversy surrounding this strategy stands in stark contrast to the increasing contention and polarization of specific climate policies and technologies, as illustrated by the Yellow Vests movement in France and demonstrations against wind parks in Norway. Such controversies are highly visible in media discourses, where fundamentally different views on the need for societal change feature in competing narratives. Energy efficiency can be part of such disputes on both sides of the argument (e.g., for or against wind parks), but controversy is rarely directed toward the concept itself. Strategies to promote energy efficiency are seemingly without contention and provide a common ground to merge otherwise opposing positions. In this article, we examine the specific logic inscribed in the concept of energy efficiency in Norwegian media discourse.' That is, our main concern is not to discuss what energy efficiency really means, but to understand its usage in Norwegian news media discourse and the underlying logic founding this use.

Throughout this article, we show how concepts such as energy efficiency and energy savings are used interchangeably in media discourse, often so that one term is included in the other. Independent of media discourse, our understanding agrees with Oikonomou et al. (2009) in that energy efficiency concerns the technical ratio between the quantity of primary or final energy consumed and the quantity of energy services obtainable, while energy saving addresses reductions in final energy consumption through behavioral changes. However, delving into the expansive energy efficiency literature, it is clear that the energy efficiency concept is ontologically ambiguous (Dunlop, 2019, p. 9). Therefore, as its meaning changes depending on context, so does its perceived utility. Wilhite and Nørgård (2004) contend that energy sustainability discourse suffers from self-deception, which revolves around equating efficiency with reduction (p. 992). This self-deception partly springs out of concealment of-or refusal to acknowledge-absolute planetary limits (Jackson, 2017). It is also connected to the complex relationship between energy efficiency and energy demand, most commonly framed as rebound effects counteracting energy efficiency gains (Herring, 2006; Wei \& Liu, 2017). Jackson (2017) summarizes the rebound critique regarding passive energy efficiency policies as the implication of driving growth forward, where relative decoupling sometimes has the perverse potential to decrease the chances for absolute decoupling (p. 111). ${ }^{2}$ Sorrell (2015) argues that similar comments apply to behavioral change, or sufficiency, since this can also have unintended consequences and necessarily involves swimming against a strong tide (p. 78). However, as Jackson (2017) claims, even if we leave the economic growth paradigm, efficiently using energy and materials remains a core foundation of the economy of tomorrow. Thus, almost regardless of the perspective on societal change, energy efficiency is a solution that either fuels continued green growth (European Commission, 2016; Sakai et al., 2019) or serves as a component in a future (non-growth) economy and provides necessities while respecting planetary limits (Jackson, 2017; Wilhite \& Nørgård, 2004).

Energy efficiency's seeming ability to bridge, or at least be part of, these otherwise incommensurable visions of the future has gained attention from criticsarguing thatenergy efficiency policies promote the status quo, essentially legitimizing ongoing energy-intensive practices (Shove, 1998, 2010, 2018) and hegemonic discourses of economic growth (Ruzzenenti \& Wagner, 2018). Lutzenhiser (2014) notes that the dominant view of consumption and energy savings works as a legitimizing logic, offering energy efficiency activities some degree of protection from political opponents and other potential critics (p. 143). Thus, energy efficiency and savings are not only scientific concepts used to describe machine performances and optimize consumer products and industry processes, nor behavioral changes reducing energy consumption. They feature in modern language, political strategy documents, and discourses as taken-for-granted concepts legitimizing narratives about the state of the world. Following this line of thought, we investigate public narratives and media events about energy efficiency and savings.

Our investigations are based on a media analysis of 309 articles in a selection of Norwegian newspapers containing the term "industrial energy efficiency," spanning 2013-2018. We specifically examine how the concepts of energy efficiency and savings are used in Norwegian media discourse. The objective of this paper is twofold. First, we set out to investigate these concepts' framings in media discourse. Through an empirical and theoretical exploration of the objectification of energy efficiency, we show how the concept's interpretive flexibility stems from black-boxing what energy efficiency is and what it can do. While we focus on energy efficiency, we explore how it is associated with energy savings and other outcomes by analyzing the explicit and implicit meaning of the concepts in use. We claim that energy efficiency draws legitimacy from a repertoire of possible and non-excluded associated interpretations. Within science and technology studies, objects that translate across social worlds are often referred to as boundary

\footnotetext{
1 A first draft of this article was published as a conference paper presented at the European Council for an Energy Efficient Economy (ECEEE 2019) Conference (Johansen et al., 2019). 2 Jackson (2017) distinguish between relative and absolute decoupling. The former refers to any decline in the material (or energy) intensity of economic output. Absolute decoupling refers to the situation when resource use (or emissions) decline in absolute terms, even as economic output continues to rise (p. 84).
} 


\section{$\$$}

NORDIC JOURNAL

of Science and Technology Studies

objects (Star \& Griesemer, 1989); similarly, we assess how energy efficiency as a concept in a media discourse produces consensus across social worlds.

Second, we investigate how narratives, controversies, and positions are legitimized by employing energy efficiency rhetoric. Our analysis shows how the concept appears 1) as a strategy to reduce emissions by minimizing energy consumption, 2) as a solution to ensure a competitive Norwegian industry and therefore economic stability and growth, and 3 ) in narratives of green growth by explaining how emissions and economic prosperity can be decoupled. While we assert that the "discourse-as-usual" revolves around consensus, there are a few examples where consensus temporarily dissipates and the inherent conflict between actors fronting different narratives and positions becomes visible. We conceptualize these media events as glitches 3 : anomalies where consensus toward a concept temporarily breaks down before returning to normal. Glitches provide an analytical opportunity to investigate what happens when concepts no longer function as boundary-spanning, allowing the exploration of the discourseas-usual's underlying structure and logic. This paper examines one glitch of particular interest to illustrate energy efficiency's function in Norwegian media discourse: a media event where six consecutive articles debate the meaning and effects of energy efficiency. Drawing on Bateson (2000) and the notion of black boxes as explanatory principles, we investigate the production of consensus surrounding energy efficiency, and how it breaks down in the glitch.

We start with a contextual description of energy efficiency as a concept and political instrument in Norway. Then, we provide an overview of our theoretical and methodological approach. Our analytical section outlines the objectification of energy efficiency in Norwegian media discourse and how the multitude of meanings and assumed effects are black-boxed. Further, we show how energy efficiency produces consensus across different social worlds and opposing positions. Finally, we show how consensus surrounding energy efficiency breaks down during a media event we conceptualize as a glitch. We conclude by discussing the importance of the glitch being temporary and not a lasting breakdown of consensus discourse. This not only provides insight into the discursive structuring but also the inherent interests behind preserving this discourse-as-usual.

\section{Energy Efficiency and Savings}

In this article, we discuss various views, interpretations, and usages of the terms energy efficiency and savings as found in our empirical data from Norwegian news media. Before presenting and discussing the empirical findings, we clarify our understanding of the key concepts included in the empirical material through other actors.
Energy efficiency and savings refer to two different microeconomic situations. As a technical term, energy efficiency refers to using less energy to produce the same amount of services or input (Patterson, 1996, p. 377). The European Commission (2016) adopts a similar definition: "the ratio of output of performance, service, goods or energy, to input of energy." Drawing on Kempton and Montgomery's (1982) notion that energy and energy use are essentially invisible to consumers, Lutzenhiser (2014) argues, "If it were possible for something to be doubly invisible, that something would be energy efficiency - the invisible, unnotable, generally imprecisely estimable phenomenon that did not occur" (p. 142). Yet, this invisible phenomenon is made visible in objects or representations of energy efficiency, taking the form of numbers, models, and ratios (Patterson, 1996). Further, as Patterson (1996) notes, energy efficiency is a generic term, for it has no unequivocal quantitative measure (p. 377). Along similar lines, Shove (2018) tells that even technical definitions of energy efficiency are permeated by normative assumptions of what is regarded "same service" or "useful output." In other words, ideal machine performance is not always a known state nor an appropriate unit of comparison when the system boundaries expand to an organization, industry sector, or country. Critique is also directed to the upper side of the energy efficiency divider, namely, energy. As illustrated by Shove (2018), energy efficiency discriminates contextually situated methods of knowing energy (e.g., manpower) in favor of contemporary generic metrics (e.g., kWh, joules), which are more easily aggregated. The connection between technical efficiency and reduced energy demand is not straightforward, as illustrated in studies on the interconnection between household efficiency and demand (Gram-Hanssen, 2014). The efficiency of technology and related infrastructures is merely one of several elements constituting the practices behind energy consumption (Gram-Hanssen, 2014, p. 104).

Energy saving, meanwhile, refers to the actual reduction of energy use without reference to output produced (Erbach, 2015). Energy saving (or conservation) also includes behavioral changes to promote energy conservation (Oikonomou et al., 2009; Steg, 2008) by using smaller quantities of energy services (Svensson \& Paramonova, 2017). The clarity of this concept also suffers from various system boundaries on "where energy supposedly is saved" to demonstrate that it is not used "elsewhere." For example, as Sorrell (2015) argues, further reductions in energy demand may be achieved by reducing the demand for the relevant energy services ("sufficiency"; p. 78). However, growing incomes create strong pressure in the opposite direction. This is somewhat in line with Shove's (2010) claim that the dominating focus on individual attitudes and behaviors disregard the stabilizing powers of practices and infrastructures.

While energy efficiency and savings are different concepts, their meaning content often overlaps, even in academic discourses 


\section{$\$$}

NORDIC JOURNAL

of Science and Technology Studies

(Dunlop, 2019). Furthermore, it is important to distinguish the technical intentions and foundations of engineering and economic notions of efficiency in a particular organizational field from larger cultural currents (Lutzenhiser, 2014, p. 143). Technical definitions aside, this study's objective is to uncover these concepts' framings and use in media discourse. Rather than examine the empirical connections between efficiency and savings, we explore the rhetorical and associative connections between them and how they legitimize different policies, financial incentives, moral positions, power, and stakeholder legitimacy in Norwegian news media discourse.

\section{Energy Efficiency in the Norwegian Context}

In Norway, $93 \%$ of electricity production is hydropower, which has resulted in historically low electricity prices compared to the rest of Europe (NVE, 2019). This poses a challenge to realizing energy-saving potential (Westskog \& Winther, 2014, p. 100). Despite this, energy efficiency (and economization) 4 has been central in Norway's political agenda to enable an economically and environmentally sustainable energy system (Norwegian Ministry of Petroleum and Energy, 2016). This is demonstrated by significant public funding for energy efficiency projects (Enova, 2020), voluntary agreements with the energy-intensive industry (see Cornelis, 2019), and university/industry research projects on energy efficiency (The Research Council of Norway, 2018). The Norwegian government agency for energy efficiency, Enova, has increased funding for industry projects considerably. In the last three years (2017-2019), the agency has contributed over 10 billion NOK in subsidies to energy efficiency and renewable energy projects, with reported energy results of $5182 \mathrm{GWh}$ (Enova, 2020). In addition, significant government funding is directed at energy efficiency research projects through the Norwegian Research Council. The most prominent is the research program Centers for Environmentally Friendly Energy, which seeks to develop expertise and promote innovation through long-term research in selected areas of environmentally friendly energy (The Research Council of Norway, 2018). The largest research center in the program is the one focusing on industrial energy efficiency.

Norwegian discourse on energy efficiency also engages with climate policies characterized by more controversy. Plans for expanding the transmission capacity of electricity to accommodate increased peak demand due to electric vehicles (EV) and energy exports to European countries are permeated by conflicting logics (Westskog \& Winther, 2014). A related discussion about Norway joining the Agency for the Cooperation of Energy Regulators (ACER) has divided NGOs, unions, industries, and politicians with differing opinions on the consequences for electricity prices. Similarly, there is resistance to increased renewable energy production (e.g., Solli, 2010). Efforts to establish new wind or hydro parks to increase renewable energy production are applauded by some environmental NGOs, but meet resistance from others insisting on wildlife and nature concerns. Other examples include controversies surrounding the electrification of offshore oil production and carbon capture and storage (Røyrvik et al., 2012). In contrast, there is little contention regarding utilizing energy more efficiently in industry processes and buildings. Environmental NGOs, as well as industrial trade organizations, front energy efficiency as a key climate policy. However, perspectives on the desired effects of these policies diverge. For example, in a report by the Federation of Norwegian Industries (2016), energy efficiency is essential to projecting a future sustainable energy system where total energy consumption increases:

Energy consumption in the EU will most likely increase by 2050. Renewable energy will replace fossil fuels to a larger degree, and there will be increased energy efficiency. (p. 78, authors' translation)

Similarly, the Norwegian NGO the Norwegian Society for the Conservation of Nature/Friends of the Earth Norway (2018, authors' translation), which focuses on nature preservation in addition to mitigating climate change, draws on the prospects of energy efficiency to reduce total energy consumption:

All energy production affects the environment. The best choice will always be to reduce the consumption of energy. With the technologies that are available, it is completely possible to spend less energy to solve the same tasks. In fact, energy efficiency is a better word than energy saving.

These contradictory views (and wants) on increase or decrease in absolute energy consumption speak to the essence of the discourse we unpack in the media narratives explored in this paper.

\section{Theoretical and Philosophical Approach}

To address energy efficiency's function in media discourse and its associated connections to energy savings, we explore the concept as an explanatory principle and that of boundary objects. While the former highlights the black-boxing of the mechanisms behind an entity's explanatory power, the latter focuses on the interpretive flexibility of objects that enables them to translate across social worlds.

\footnotetext{
4 Energy economization, or ENØK, refers to policies aiming to use and produce energy more profitably, a strategy that gained momentum in Norway after the energy crisis in the 1970 (Skjølsvold et al., 2013).
} 


\section{N}

NORDIC JOURNAL

of Science and Technology Studies

\section{Systems of Dependency}

While energy efficiency's technical definitions are equivocal and rely on normative assumptions, the concept has entered modern language and policy documents as a malleable generic term. Its usage can be understood in terms of what Bateson (2000) calls an explanatory principle. An explanatory principle emerges through a process of objectification, implying that the phenomena gathered into an object gain a certain gravity (Larsen, 2010) and become increasingly self-sufficient. At this point, the object achieves the qualities of an explanatory principle, explaining something without itself being in need of explanation (Bateson, 2000, p. 39). However, at the same time that the concept gains its object qualities, it conceals its ambiguous nature. Thus, an explanatory principle is likened to a black box:

It's a word that comes from the engineers. When they draw a diagram of a complicated machine, they use a sort of shorthand. Instead of drawing all the details, they put a box to stand for a whole bunch of parts and label the box with what that bunch of parts is supposed to do. (Bateson, 2000, p. 41)

The explanatory principle indicates that there is no need to explain a thing further. While the input and output of a black box are known, the mechanism inside is concealed. It does its job whether one knows the mechanism inside or not. This aspect of concealment is highlighted in the term black-boxing (e.g., Latour, 1999). Keeping with Bateson's cybernetic take on black boxes and explanatory principles, their roles in larger systems are important. In an engineering drawing, the black box plays an essential role that can be seen as a system of explanation. The parts make up a whole, which has certain qualities one cannot derive from the individual parts. However, the whole system depends on the individual parts. If you remove one black box, the machine will not work, and the engineering drawing loses its explanatory power. As this illustrates, Bateson's systems theory is cybernetic and highlights the ontological relation between the parts and the whole (Bateson, 2000).

The nature of dependency is particularly relevant in this respect, and it is possible to see explanatory principles in the same way. ${ }^{5}$ As larger systems of explanation are built on black boxes, they cannot be removed since so much is invested in them. The concept of energy efficiency also seems to be weaved into larger systems that have become dependent on it, including explanatory, political, and economic systems. ${ }^{6}$ The concept and the system are mutually dependent on each other: the concept, as an explanatory principle, legitimizes the larger system, and the larger system legitimizes the explanatory principle. As energy efficiency also figures into scientific arguments and systems of explanations, it can be seen in light of Heidegger's (1977) Gestell, which can shed light on certain aspects of Bateson's systems of explanations. Specifically,
Heidegger (1977) points to how certain objects are gathered as "facts" that legitimize an "explanation" while they themselves are confirmed by the same explanation.

\section{Boundary Objects}

In this article, we analyze energy efficiency as a media object able to unite adversaries across different discourses and social groups. Thus, we assess its characteristics as a boundary object. Star and Griesemer (1989) introduce the boundary object concept to characterize museum artefacts used differently by experts and amateurs, translating between groups:

Objects which are both plastic enough to adapt to local needs and constraints of the several parties employing them, yet robust enough to maintain a common identity across sites. They are weakly structured in common use, and become strongly structured in individual-site use. They may be abstract or concrete. They have different meanings in different social worlds but their structure is common enough to more than one world to make them recognizable, a means of translation. The creation and management of boundary objects is key in developing and maintaining coherence across intersecting social worlds. (p. 393)

Boundary objects are rarely neutral, as there is a risk of them favoring perspectives that are more easily articulated by the objects (Carlile, 2004). The concept is also used in studies of interdisciplinary cooperation, emphasizing the boundary object's role in connecting experts through collaboration (Wenger, 1998). Here, the boundary object is typically a technical model on which different experts can work and thus articulate their perspectives in the collaboration. Boundary objects have also been explored as concepts transcending social worlds on a macro level (e.g. Brand \& Jax, 2007). As such, we examine the characteristics of the concept of energy efficiency in the discourse with the function of a boundary object.

\section{Discourse Analysis}

In this article, we focus on the discursive patterns in public communication that include the term energy efficiency and associated concepts. First treated as a formal and administrative concept, energy efficiency turned into a word used in spoken conversation and increasingly in newspaper media articles. Discourse analysis examines the conditions of knowing by questioning discursive objects (Foucault, 1977), revealing power and their regimes of knowledge as expressed in public communication. As a result, a core idea within critical discourse analysis is that knowledge is always situated and legitimizes power (Foucault, 1977). Thus, by focusing on the patterns in public communication, what is taken for granted, natural, and seen as the natural order of things is questioned. While Foucault (1977) refers to discourse as "ways of constituting knowledge" that govern the way a topic 


\section{$\$$}

NORDIC JOURNAL

of Science and Technology Studies

can be meaningfully talked and reasoned about, Bourdieu (1977) treats it as a "structuring, structured, structure." This implies a kind of power that is non-personal in that it is a structuring of the thinking that is already structured by what was possible to think and express - a continuing reification of thought, structure, and power.

In our text corpus, such reification is expressed by the generic use of concepts where the relations between energy efficiency, reduction, and sustainability are not clear. To analyze the concept of energy efficiency, we observe how it is constituted as a word, that is, how a techno-social phenomenon is assigned certain object qualities, gathered, and separated from other phenomena and related as either cause or effect in the discourse of explanations (Bye et al., 2016; Heidegger, 2001; Røyrvik et al., 2012). In this case, the objectification process of energy efficiency is analyzed according to how the word is delimited (in different ways) and used (differently) to form arguments within narratives.

\section{Methodological Approach}

We analyzed framings of industrial energy efficiency and savings by studying articles in Norwegian online newspapers from January 1, 2013 to January 1, 2018. Eight different Norwegian newspapers were selected to cover different segments of the public debate, including newspapers with different topical (political, technical, and daily newspapers) and geographical (local, regional, and national) foci: Dagens Neringsliv, Klassekampen, Verdens Gang, Aftenposten, Adresseavisa, Rana Blad, Varden, and Teknisk Ukeblad. Of the 326 articles gathered through the web database Retriever, 309 were analyzed and coded in-depth after removing nonrelevant articles.

Initially, we explored several search criteria to capture the different framings of energy efficiency, savings, and reductions. The final search parameters were the word industry in combination with one of the following Norwegian equivalents: energy efficiency, energyefficiency, energy economization, energy efficient, energy reduction, energy saving, and save energy. We coded the articles in Norwegian and translated the selected quotes for this paper to English after the analysis. By coding the meaning content of the words as used in the discourse, we sought to avoid translation issues between Norwegian and English. We coded whether the authors provided explicit definitions or expressed meaning content of the concept in terms of how they linked to technical efficiency ("less for more" relationships), behavioral change, and absolute energy reductions (output). We also coded if the concepts were framed in the articles as merely generic words or entities without expressed (or obviously implicit) meaning content. In this way, we sought to capture not only the academic definitions of the concept, but also investigate the larger cultural currents of meaning content in media discourse.

Further, we coded the articles according to 18 categories. ${ }^{7}$ The most relevant here are "main narrative" and "media events." In our emergent coding, we identified four narratives in which energy efficiency and savings featured as a solution: narratives of climate change, economic change, green growth, and reliable energy supply. These broad narratives carry with them an array of diverse sub-narratives, positions, and arguments. The purpose of this study was to investigate how the concept of energy efficiency appears within them and legitimizes argumentations (and not explore all avenues of the narratives themselves). ${ }^{8}$ We also found and registered media events, that is, cases where two or more articles revolved around a specific news story (e.g., wind park controversies, climate conventions). While rare in our material, we found a few media events where contention turned toward the concept of energy efficiency itself. What makes these anomalies interesting is not their frequency, but their rarity. We focus on one particular glitch in this paper, as it triggered a debate over the concept of energy efficiency spanning several news articles. Here, our analytical approach was inspired by Latour's (2005) advice to "feed controversies" and focus on issues that are controversial and subject to debate or disagreement (p. 21). This implied expanding our analysis and following a media event we characterized as a glitch as an opportunity to understand both the peculiarity of these situations and the discourse-as-usual.

Investigating "breakdowns" to understand "order" is a viable research strategy used in studies of societal norms in ethnomethodology (Garfinkel, 1967), as well as conflict studies in the Manchester School. The overall methodological principle can nevertheless be referred to as phenomenological-inspired hermeneutics (Geertz, 1973). We seek to understand the whole (the conceptualization of energy efficiency) through a focus on a specific part (an anomaly in the media discourse) to examine the world view (narratives on societal change) through which the concept emerges. ${ }^{9}$ In the following sections, we investigate the objectification of energy efficiency in media discourse, how it produces consensus, and what the temporary dissolvent of consensus during a glitch can tell us about the discourse-as-usual.

\footnotetext{
7 Article identification number (v1), newspaper (v2), article name (v3), date (v4), genre (v5), size (v6), theme (v7), local/national/international level (v8), industry case (vg), actors mentioned (v10), text producer (v11), sources (primary, secondary, tertiary) (v12), media event (v13), main narrative (v14), associated sub-narratives (v15), and the author's position within narratives (positive, negative, neutral, conflict) (v16). Finally, we coded which concepts were used for energy efficiency/savings (v17) and included a comment variable coding these concepts' explicit/implicit framings (v18).

8 Note that these narratives are empirically derived from the research design and search words on energy efficiency and reductions.

9 As Douglas (1966) shows, anomalies are of particular interest both for anthropologists to explain and for societies to manage.
} 


\section{Discourse-as-Usual: \\ Energy Efficiency in Norwegian News Media}

Within the Norwegian news discourse, energy efficiency and savings entail different meanings and causal outcomes ready for application within different arguments. Tracing the concept's usage in newspaper articles, it is evident that it holds both different referents and references (e.g., Bye et al., 2016), sometimes within an article but especially between articles. However, the concepts are most commonly used generically without explicit references and explanations. Next, we briefly present the discourse-as-usual and how energy efficiency is subject to processes of objectification and attributed a multitude of possible characteristics.

\section{The Objectification of Energy Efficiency and Savings}

The term energy efficiency was increasingly used in Norwegian news media during the period studied. Most often, the concept is not explicitly explained, but there are two characteristics of what energy efficiency and savings "do" that are expressed, namely entailing relative or absolute reductions in energy consumption. Several articles express a "more for less" characteristic of energy efficiency through ratios, comparisons, energy results, or explanations. This reflects modern definitions of energy efficiency (Patterson, 1996), explained in articles as "energy efficiency - to do more with less energy - is one of the instruments"10 or through explicit ratios expressing amounts of products divided by energy. There is a large variance on the specification of the parameters (the more and the less), ranging from purely generic to explicit energy efficiency indicators (e.g., energy divided by tons of aluminum).

Other articles attribute reductions in energy consumption to a characteristic of energy efficiency or as a direct effect of efficiency: for example, "the solution is to reduce the winter consumption of electricity through energy efficiency and heating methods requiring low or none electricity." ${ }^{\prime 1}$ These effects of energy efficiency are also expressed in absolute numbers, as with, "Energy efficiency will reduce the electricity demand heavily, up to 15 TWh."12 Here, the causal effect-what energy efficiency does-is reducing overall energy consumption. Reducing energy consumption (or energy saving) is usually framed within a climate narrative and expressed through popular sayings such as, "The most climatefriendly kilowatt there is, is the one that will never be used."13 Such statements connect the climate aspect to reduced energy consumption. Only a few articles explicitly frame lower quantities of energy services through behavioral change-and in these cases, individuals must change their behavior (and not companies or larger systems). Thus, energy efficiency is given different meanings in different articles, diverging from the academic definitions of the concepts.

Most commonly, the concepts are used as generic words. When used without definitions or explanations, they tend to feature as a self-explanatory entity causally related to other entities, such as in the example below:

Renewable energy and energy efficiency are important strategies to increase energy security in Europe, but also to decrease climate gas emissions and create new jobs. (Politician, Labor Party, Aftenposten, 08.13.2017)

It is in this causal relationship (as either a cause or an effect) that the entity's function is revealed. Connections are made between the concept and assumed effects and multiple benefits, such as energy security, emission reduction, and job creation. In such arguments, the uncharacterized entity can cause all these effects. Another example of generic framing formulates the concept of energy efficiency as an adjective or quality statement. The purpose of the quality statements within the arguments, as with the one below, is to underline the efficiency of something:

The main competitive advantage of Norwegian industry is that it is very energy efficient and utilizes clean, renewable hydroelectric power as an energy source. (Journalist, Varden, 11.01.2016)

It is not only the meaning that varies in and between articles, but also the object that "is" energy efficient, from a product or organization in some articles to industry sectors or countries in others. The temporal and spatial system boundaries of the energy efficient object diverge (e.g., the world, previous practices), as does the object of comparison (e.g., industry in other countries). Thus, energy efficiency-as a media object-is attributed properties through the functions that it holds in different contexts. As such, meaning is inscribed to the entity by its attributed properties while also concealing the meaning of the word in the same objectification process. ${ }^{14}$

\section{Consensus across Narratives, Controversies, Levels, and Positions}

We find there is almost no controversy about energy efficiency itself in news discourse, but it is used-and has a function-in various arguments in other controversies in the Norwegian context. In the following section, we elaborate on the narratives and media events

10 Journalist, Klassekampen, 01.19.2013

11 Statnett representative, Teknisk Ukeblad, 03.27.2014

12 ZERO, Aftenposten, 12.18.2013.

13 Journalist, Dagens Næringsliv, 02.27.2016.

14 Resembling the way Latour (e.g., 1999) asserts that objects are defined. 
in which energy efficiency and savings feature. We focus on the breadth (rather than depth) of discussion to show the "multiple benefits" associated with and legitimized by the concepts in news media discourse.

We identified three main narratives in which energy efficiency serves as a solution. Common to all three are different types of societal change and the need to address these changes. ${ }^{15}$ The narratives are also prominent at different levels (global, national, and local). The first narrative, labeled "climate/environment narrative" (40\%), includes articles placing arguments within a narrative of climate change. The second narrative, labeled "economic stability and growth" (16\%), contains articles concerning economic growth and industrial stability. The third narrative, which we labeled "green growth" (16\%), comments on the interlinking and decoupling between climate change and industrial growth. ${ }^{16}$ Within the narratives, energy efficiency is framed as a solution and often referred to in arguments that mention several strategies, as in the example below:

A new course in climate politics would require more full-scale CCS, renewable energy, energy efficiency, funding to adjust industries, and more electric cars on the road. (Journalist, Klassekampen, 09.28.2013)

While energy efficiency features in similar ways as a solution in the other narratives, it differs in terms of solving different things (as summarized in Table 1).

\section{TRANSITION NARRATIVES AND FRAMINGS OF ENERGY EFFICIENCY}

\begin{tabular}{|c|c|c|c|}
\hline & Climate narrative & Economic narrative & Green growth narrative \\
\hline $\begin{array}{l}\text { Energy efficiency within } \\
\text { the change narrative }\end{array}$ & $\begin{array}{l}\text { Energy efficiency is one of the } \\
\text { strategies to address climate } \\
\text { change by reducing energy } \\
\text { consumption, which can displace } \\
\text { carbon-intensive practices } \\
\text { elsewhere through the export } \\
\text { of electricity or products. }\end{array}$ & $\begin{array}{l}\text { Energy efficiency is vital to ensuring } \\
\text { economic competitiveness and } \\
\text { growth in Norwegian industry. }\end{array}$ & $\begin{array}{l}\text { Energy efficiency is important } \\
\text { to enabling economic growth } \\
\text { and reaching climate targets } \\
\text { (decoupling). Increased energy- } \\
\text { efficient production in Norway } \\
\text { can displace carbon-intensive } \\
\text { practices elsewhere. }\end{array}$ \\
\hline
\end{tabular}

Table 1. Transition narratives and framings of energy efficiency.

Within the transition narratives, there are several ongoing controversies where energy efficiency also has a function on both sides of a given argument. The most prominent of these in our data material is that of the development of onshore wind parks, hydro parks, and transmission lines, which splits politicians and NGOs calling for nature preservation and local democracy on the one hand and climate change mitigation and energy security on the other ("Nature/Climate"). A second prominent controversy is the debate concerning the increase of transmission capacity to Europe ("Green battery for Europe/Green industry in Norway"). Here, the main topic of contention is the impact on energy prices for Norwegian industry. A third controversy is the future of the Norwegian oil and gas industry, where specific controversy concerns the possible expansion of Norwegian oil and gas fields in the Arctic region or whether this industry should be phased out ("Sustainable oil and gas/Phase out"). Arguments connect to the transitions narratives by establishing logical pathways including or excluding the object of contention. Here, the use of the energy efficiency concept functions as an alternative within the argument, as in the "Nature/Climate" controversy below:

The proposed wind park build out is ruthless, massive in scale, and does not acknowledge the consequences and impact on nature in Trøndelag. We have to oppose it. As an alternative, we should pursue energy economization and reduced consumption and upgrade existing hydropower, transmission networks, and other renewable energy sources, such as solar, geothermal energy, and offshore wind. (Politician, Adresseavisa, 09.04.2013)

While this stance establishes a climate narrative, energy economization and reduced consumption form a more favorable pathway than establishing wind parks. Similarly, establishing electricity transmission lines triggered opposition in a local newspaper, where energy efficiency is the preferred alternative to constructing transmission lines:

The best would of course be to not construct the [transmission] line. Instead, the billions could be used on families and industry in Trøndelag so they can upgrade buildings, install heat pumps, and pursue energy efficiency. (NGO, Adresseavisa 06.03.2013)

We find similar views in all controversies and media events in our data material. While the articles' authors front opposing positions between narratives or within a more specific controversy, the energy efficiency concept enters the argumentation as rhetorical ammunition on both sides. In these controversies, the actors employ

15 In scholarly debates, these changes tend to be addressed as transformations or transitions (e.g., Jørgensen, 2012).

16 We also find a narrative of reliable energy supply ( $16 \%$ of articles) in which energy efficiency features. We do not address this narrative further in this article. 
energy efficiency to legitimize their positions and narratives. The concept seems to create a shared understanding of at least one of the elements that needs to be done (energy efficiency) to solve the problems at hand.

\section{Breaking Consensus with Limits: More for Less, but Increased Absolute Energy Consumption}

While energy efficiency is not an object of controversy in the discourse-as-usual, we found a few examples where consensus surrounding energy efficiency temporarily dissipates. Here, the inherent conflict between actors, narratives and positions becomes visible as a conflict regarding the meaning of energy efficiency itself. In the following section, we explore one such controversy in depth, involving a media event that caused a temporary breakdown in consensus surrounding the prospects of energy efficiency as a solution in both a climate and economic growth narrative.

Following a national conference for energy efficiency and the environment arranged by Enova in January 2013, the former Norwegian Oil and Energy Minister Ola Borten Moe stated that the government's objective was to increase energy efficiency and increase energy consumption, as reported in the business newspaper Dagens Nceringsliv (01.30.2013):

The Norwegian government will not put a cap on energy use and is not against increased energy use. We are at the same time engaged with energy efficiency and wish to produce more for less, said Borten Moe.

Over the next three days, this statement led to several articles debating the concept of energy efficiency and the connection between energy efficiency and national carbon reduction objectives. ${ }^{17}$ Journalists argued the paradox of fronting energy efficiency as a climate policy if the objective was not an absolute reduction in energy consumption. For instance, the regional newspaper, Adresseavisa published a critical short-article called "Unclear about Climate Objectives":

Yesterday, the responsible cabinet minister for Enova contributed to confusion regarding the government's ambition for climate change mitigation. Several of the 700 listeners at the Enova conference were puzzled when Ola Borten Moe emphasized that the government would not set a cap on energy use and emissions. "From my point of view, it is good if we can both increase energy efficiency and at the same time increase the total energy consumption. That means we have succeeded, that we increase the value creation and employment in Norway," he said. It is nice that the cabinet member thinks outside the red-green box. What is challenging is that this statement about increasing energy consumption makes it even more unclear what the government will achieve with climate efforts and Enova as an instrument. "Oil Ola" must beware so that he doesn't become "Waste Ola." (Newspaper Leader, Adresseavisa, $01.30 .2013)$

This argument centers on how energy efficiency policies can contribute to climate targets if the objective is to increase energy consumption. Further, the newspaper challenged Enova on whether their financial support of energy efficiency projects are actually industry policy incentives rather than climate efforts. Enova's director agreed that absolute energy consumption might in fact increase despite efficiency efforts:

We are concerned with efficient energy use, and that means that energy consumption as such may increase. But the increase in the industry sector will hopefully come at the cost of, for example, aluminum production produced with non-renewable energy outside Norway. (Enova director, Adresseavisa 01.30.2013)

When challenged on using the word "hopefully," the director had to agree that there was no way to measure or know for sure that the increased production of goods in Norway would lead to reduced production and related carbon emissions elsewhere. Other articles lent support to the stance that improved energy efficiency and increased energy consumption were in fact positive outcomes. An advisor from the same political party supported and explained what the minister said in a short article entitled "To Get More Out of Less":

If we increase energy efficiency, we strengthen both value creation and employment rates in Norway. This means that we produce more for less. Resource efficiency and reduced $\mathrm{CO}_{2}$ emissions are central. (Political advisor, Adresseavisa 02.01.2013)

In this statement, the main narrative is one of value creation and economic growth, where energy efficiency entails producing more for less and strengthening competitiveness. Other actors also took sides in criticizing the newspaper for confusing their audience, stating that increased energy consumption was a wanted outcome as long as it was more energy efficient. In this media event, the apparent agreement (on a number of levels) dissolved, and the confronting views on what energy efficiency is and what it can and should do surfaced when confronted with absolute limits. Two days later, the media event was over. In fact, ten days later an article in the same newspaper proclaimed that energy efficiency was a vital climate strategy. Thus, the controversy became a mere glitch in the discourse-as-usual. 


\section{Producing Consensus in a Discourse-as-Usual}

It is apparent that several of the actors do not address the same phenomena nor their effects when drawing on the familiar concepts of energy efficiency, savings, and reduction. The multitude of associations, combined with the overwhelming tendency to utilize energy efficiency as a generic word (either as a description, quality statement, or entity), contributes to black-boxing what energy efficiency is and what it can do. Thus, energy efficiency as an object encompasses a repertoire of associative meanings and effects. Indeed, in most articles, the links between the concept and the repertoire of possible associations and effects are black-boxed (as illustrated in Figure 1). As such, energy efficiency relates to different academic definitions and actors' interpretations of energy efficiency and savings through associations only. Yet, the entity appears scientific and conveys scientific legitimacy.

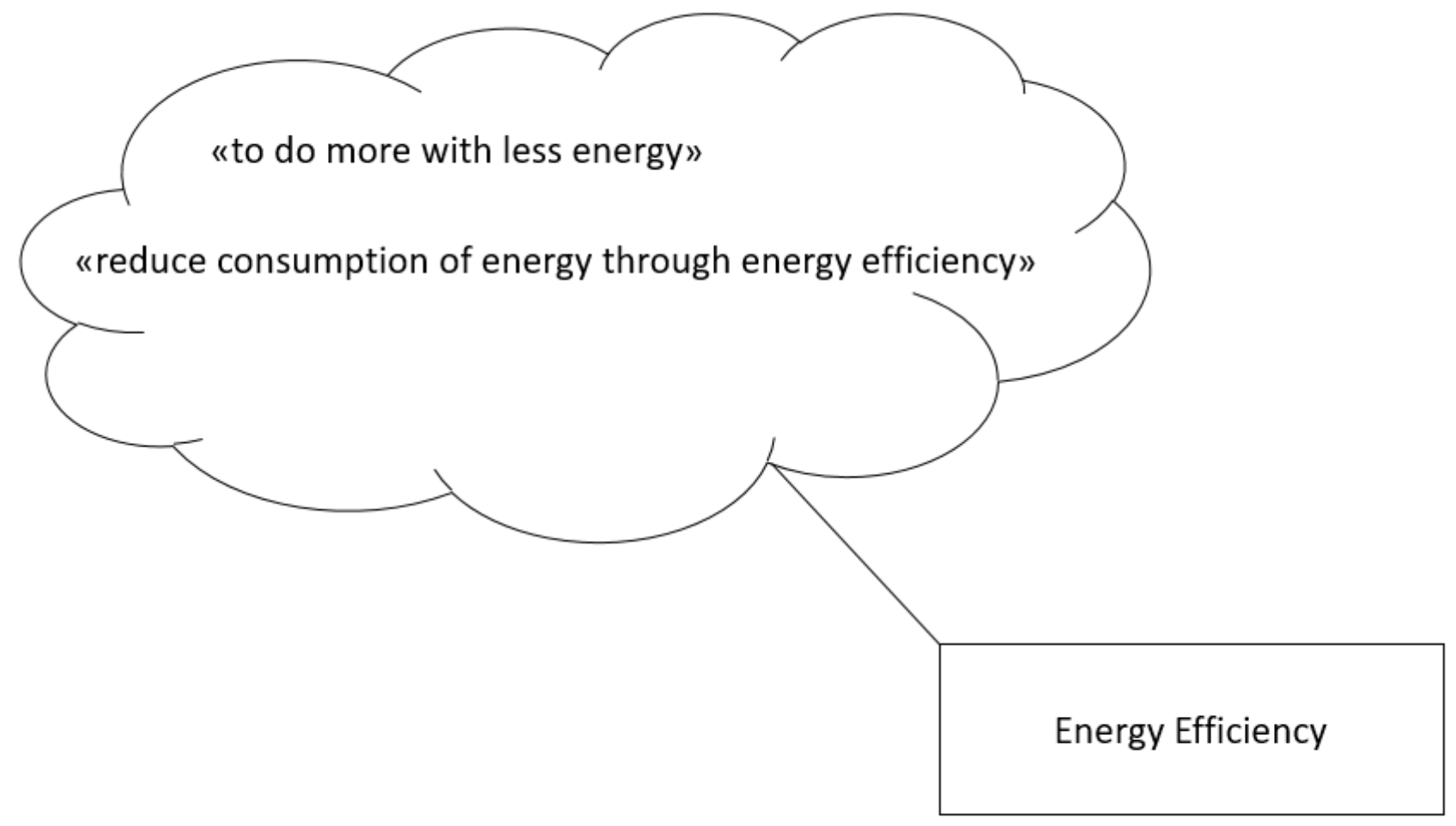

Figure 1: Illustration of how energy efficiency as a black box draws attributes from a repertoire of associations

A main finding in our data is that the energy efficiency concept is seldom the focus of contention or the main article topic. This can be partially attributed to the invisibility of energy (Kempton \& Montgomery, 1982) and energy efficiency in particular (Lutzenhiser, 2014). However, the concept is visible in debates, featuring within argumentations of opposing positions in media narratives and specific controversies and thereby producing consensus without revealing the mutual exclusiveness of the positions. Actors who stand on different sides of media controversies all agree on the need for energy efficiency and employ the concept in their claims. Even within controversies such as local wind parks, transmission lines to Europe, the future of the Norwegian oil and gas industry, and electricity prices, actors employ the concept and effects of energy efficiency to legitimize their "for" or "against" statements. In this way, energy efficiency is a flexible media object that can legitimize opposing arguments, as well as converge narratives (as illustrated in Figure 2). 


\section{Narratives}

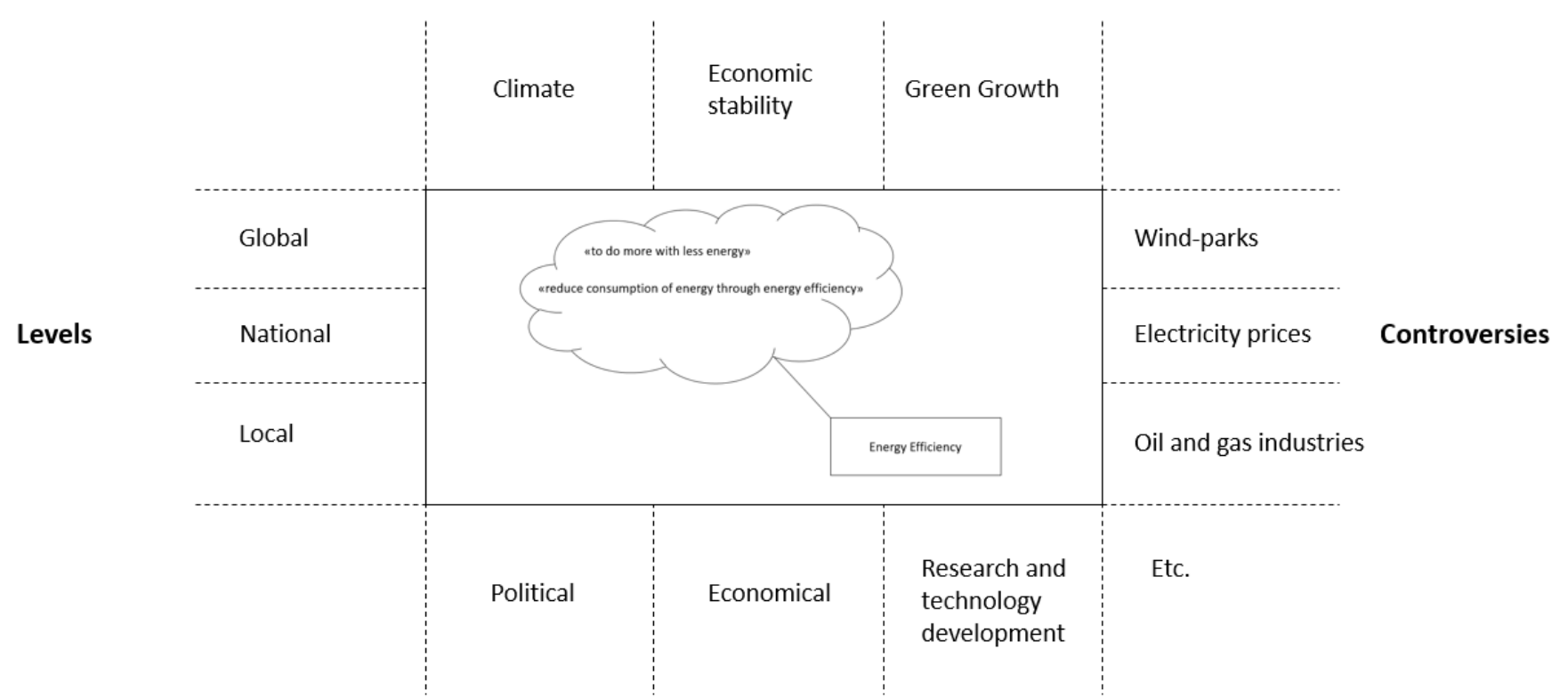

Spheres

Figure 2: Illustration of how energy efficiency translates across narratives, controversies, levels, and spheres

Energy efficiency is a concept that bridges opposing positions and narratives, thus sharing characteristics with boundary objects. According to Star and Griesemer (1989), boundary objects function as translation tools between different social worlds and can be products, people, discourses, or processes (p. 387). A boundary object is adaptive to different views, but also robust enough to maintain its identity across these views. While there is contention surrounding what is and is not a boundary object (Star, 2010), energy efficiency shares characteristics with boundary objects in the way it functions in Norwegian media discourse: it seemingly translates between narratives, opposing positions, and levels, producing consensus in the discourse-as-usual.

\section{Breakdown of the Boundary Object}

Similar to other boundary objects (e.g., Brand \& Jax, 2007), the descriptive and generic use of energy efficiency makes it malleable to accommodate different narratives and positions. The interchangeable use of concepts and meaning content partly reflects what Wilhite and Nørgård (2004) argue is a self-deception in climate policy, namely, the equation between efficiency and reductions. However, rather than equating these concepts, we argue their relationship as black-boxed in media discourse. This is not only a semantical difference, though. While associating efficiency with reductions can be legitimized in a climate narrative, it is not the same in narratives of economic growth that promote increased overall energy use. The investigation of how energy efficiency features in the discourse as a black-boxed entity, concealing actors' views and wants on absolute energy reductions, provides one explanation of how it is able to unite adversaries across otherwise conflicting narratives of climate change and economic growth.

The characteristics of energy efficiency as attributed by association in media discourse are not mutually exclusive, but in the media event we labeled a glitch, they suddenly are. This moment of controversy and temporary breakdown of consensus opens a window to study the concept's taken-for-granted nature. When the Minister of Oil and Energy explicitly stated that increased energy efficiency and increased energy consumption was the wanted outcome, the link to other possible meanings and effects was disrupted, and efficiency and reductions were clearly not equated. By explicitly taking positions on the wanted effects of energy efficiency, the media event forced a discussion of what Jackson (2017) refers to as "absolute limits." Suddenly, there was disagreement about the meaning of energy efficiency as well as its desired effects. It no longer united adversaries or opposing views, and the boundary object seemed to collapse. This temporary fall of consensus indicates that the object never actually translated between oppositions. On the contrary, it illustrates the apparent translation that the concept holds in Norwegian news discourse.

In this event, we can peak inside the black box and observe the fundamental disagreements about what energy efficiency is, can, and should do. The concept's robustness in the discourse-as-usual lies in the way it can be interpreted and aligned with different narratives on societal change. The repertoire of associations lends the characteristics of a boundary object that mediates and translates between different social worlds. However, energy efficiency's interpretive flexibility shares characteristics with Schrödinger's cat: as long as we do not open the black box, energy efficiency (as a concept in media discourse) can imply both absolute reductions and absolute increases in energy consumption. When Schrödinger's cat is observed to be either alive or dead-that is, the boundary object appears to have collapsed-energy efficiency no longer translates across actors' different views on societal change. In this case, the link to the repertoire of meanings dissolves, and it is no longer possible for actors to interpret the effects of energy efficiency as only absolute energy reductions. The object loses its interpretive flexibility, at least temporarily. 


\section{Narratives}

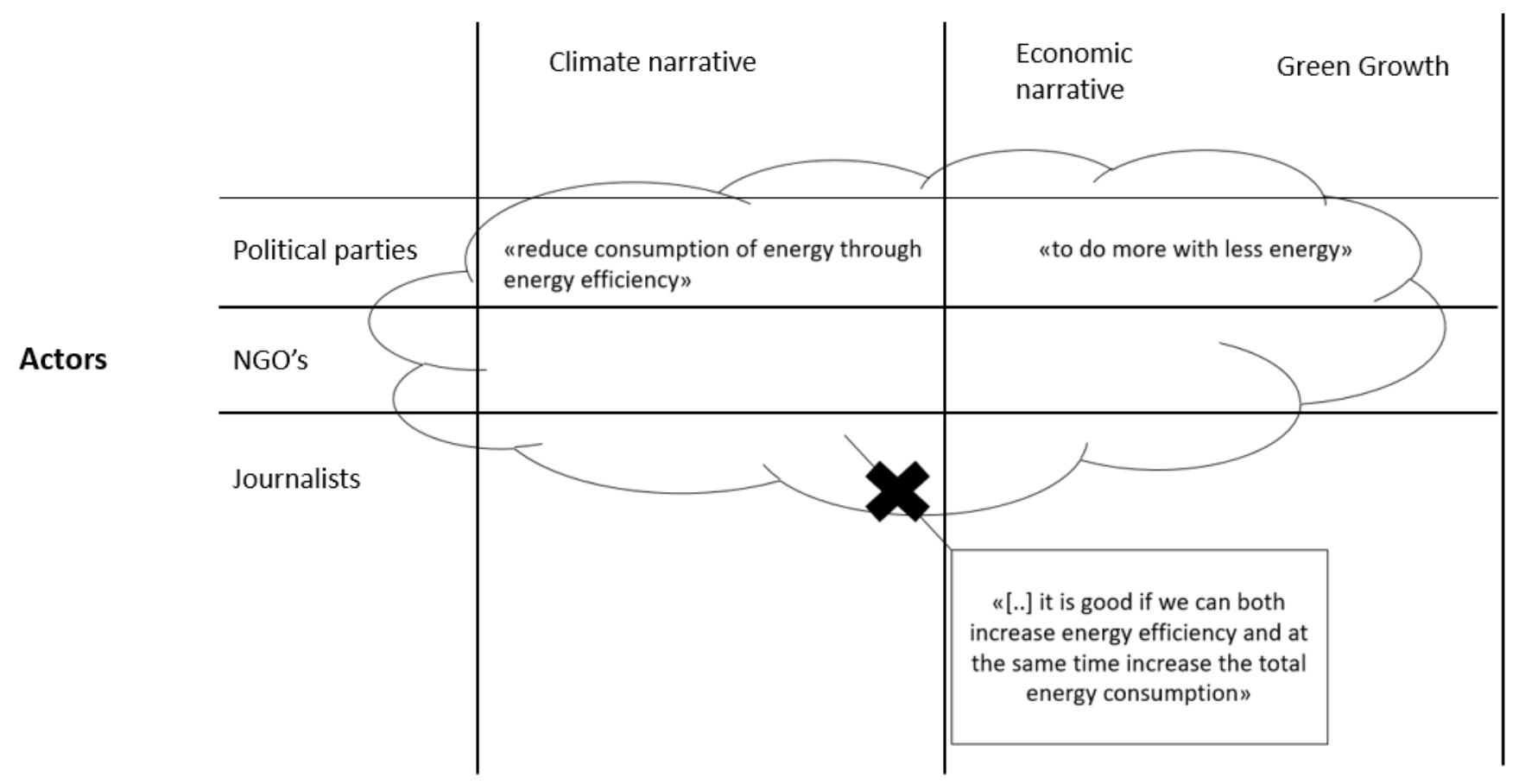

Figure 3: The glitch actualizes differences between actors fronting different narratives

By making the meaning and wanted effects of energy efficiency explicit (as illustrated by disrupting the link to alternative associations in Figure 3), differences between opposing positions are revealed. The breakdown of energy efficiency as a boundary object allows us to clearly see the oppositions in the discourse-as-usual.

\section{Glitches, not Permanent Breakdowns in the Discourse-as-Usual}

It seems that energy efficiency is able to unite adversaries because all have an interest in the concept. Researchers obtain funding by researching energy efficiency, industry can increase production by becoming more energy efficient, politicians show that they take the climate crisis seriously by arguing for energy efficiency, and NGOs fulfill their purpose by promoting energy efficiency. Researchers, industries, politicians, and NGOs depend on the various rhetorical outcomes of energy efficiency, which is also illustrated by Lutzenhiser's (2014) discussion of the dominant position of the energy efficiency industry. In Bateson's (2000) terms, we can view this as a systemic dependency on energy efficiency as a black-boxed explanatory principle. Through logics of addiction, the explanatory principle is imperative for this social system to work. It explains without a common understanding and works exactly due to this lack of shared understanding or translation across conflict lines. As such, despite differences in interest, various actors may find it better not to open this black box and rather allow the concept to work as an explanatory principle. The concept thereby achieves a gravity of its own (Larsen, 2010) that works across conflict lines. The gravity of the explanatory principle is profound, and removing it is therefore not an option. Thus, while a glitch can illuminate the different interests at play, it does not manifest in permanent policy or discourse change. In a glitch, we are able to observe the conflicts of interests, goals, and perspectives surrounding the concept. Yet, the swift normalization and the fact that they seldom happen show what seems to be a common ground between all actors to produce consent about not challenging energy efficiency, allowing everyone's activities to go on. This is why, we argue, glitches are only temporary and not breakdowns of the concept.

\section{Conclusion}

Through the present analysis, we found that energy efficiency as a black box produces consensus across different interests and narratives. The term energy efficiency is a different tool in different hands for different purposes, though it appears to be the same. 
While posing as a scientific concept, our analysis shows how it associates multiple and contradictory meanings and outcomes in media discourse, as evoked by association rather than rigorous academic definitions.

The analysis of energy efficiency's rhetorical use shows a peculiar aspect of the concept's interpretive flexibility. If interpretive flexibility flows from black-boxing fundamentally different opinions, these objects do not necessarily translate between social worlds but rather conceal differences between them. In our case, concealment in the public debate reflects what Wilhite and Nørgård (2004) call a self-deception in energy policy, the equation of more with less, and efficiency with savings and absolute reductions. However, our argument is not only a call for the correct use of these concepts. Rather, we show the conflict that arises when perspectives on the need-or refusal-to acknowledge absolute limits are made explicit. Essentially, this goes to the heart of the debate on the need for respecting absolute planetary limits (Jackson, 2017) and consequently address absolute limits to energy consumption and economic growth. Still, we found that narratives of behavioral changes, reducing energy services, and economic growth are largely missing from Norwegian media discourse. This is perhaps not surprising, as Jackson (2017) tells that the dilemma of rejecting growth is only marginally visible as a public debate (p. 211). However, a consequence of this is that discussions of energy efficiency are also mainly situated within media narratives concerning business as usual. This adds to the point made by several scholars addressing the legitimizing powers of energy efficiency, namely how it promotes a status quo discourse (Lutzenhiser, 2014; Ruzzenenti \& Wagner, 2018; Shove, 2018).
Investigating the discourse-as-usual through an anomaly provides the opportunity to pinpoint the moral prerogative of energy efficiency as a concept. It essentially allows for a complete absence of consequences. As a black-boxed entity with the flexibility to associate both relative improvements with reduced absolute energy consumption and increased absolute energy consumption, it legitimizes ongoing activity for actors working toward limiting consumption, as well as actors promoting economic growth. Only in certain and few media events do fundamentally different views on the wanted outcomes of energy efficiency and savings and opinions on the need for profound societal change versus "a more efficient business as usual" become visible. Investigating the media objects' characteristics in this example is a valuable analytical approach to investigate the structures and functions of the concept within the macro discourse and the characteristics of this discourse. With the black box opened and different meanings revealed, the concept is no longer boundary-spanning. However, both climate and economic narratives depend on energy efficiency as a black box. Thus, the contention over what energy efficiency can and should do is only temporary and quickly normalized. It becomes but a glitch and does not cause permanent changes in how we talk about energy efficiency and reductions. As Wilhite and Nørgård (2004) note, energy policy is itself torn between more and less, and the only strategy that can be rationalized as serving both is one that promotes technical energy efficiency (p. 1006). Thus, the fact that the object only temporary breaks down is perhaps not surprising. It is as an explanatory principle, producing consensus, that the concept of energy efficiency work its magic.

\section{Acknowledgements}

This paper has been funded by HighEFF - Centre for an Energy Efficient and Competitive Industry for the Future, an 8-year Research Centre under the FME-scheme (257632/E2O). The authors gratefully acknowledge the financial support from the Research Council of Norway and user partners of HighEFF. Special thanks to Gudveig Gjøsund for contribution to the research project.

\section{References}

Bateson, G. (2000). Steps to an ecology of mind: Collected essays in anthropology, psychiatry, evolution, and epistemology. University of Chicago Press.

Bourdieu, P. (1977). Outline of a theory of practice (Vol. 16). Cambridge University Press.

Brand, F., \& Jax, K. (2007). Focusing the meaning(s) of resilience: Resilience as a descriptive concept and a boundary object. Ecology and Society, 12(1): 23

Bye, R. J., Rosness, R., \& Røyrvik, J. O. D. (2016). 'Culture' as a tool and stumbling block for learning: The function of 'culture' in communications from regulatory authorities in the Norwegian petroleum sector. Safety Science, 81, 68-80.
Carlile, P. R. (2004). Transferring, translating, and transforming: An integrative framework for managing knowledge across boundaries. Organization Science, 15(5), 555-568.

Cornelis, E. (2019). History and prospect of voluntary agreements on industrial energy efficiency in Europe. Energy Policy, 132, 567-582. https://doi.org/10.1016/j.enpol.2019.06.003

Douglas, M. (1966). Purity and danger: An analysis of the concepts of pollution and taboo. Taylor and Francis.

Dunlop, T. (2019). Mind the gap: A social sciences review of energy efficiency. Energy Research \& Social Science, 56, 101216. https://doi.org/10.1016/j.erss.2019.05.026

Enova. (2020). Annual report 2019. 
https://www.enova.no/om-enova/kampanjer/arsrapporten-2019/

Erbach, G. (2015). Understanding energy efficiency. EPRS European Parliament Research Service.

http://www.europarl.europa.eu/RegData/etudes/BRIE/2015/5 68367/EPRS BRI\%282015\%29568361_EN.pdf

European Commission. (2016). European Commission - Putting energy efficiency first: consuming better, getting cleaner.

http://europa.eu/rapid/press-release MEMO-16-3986 en.htm

Foucault, M. (1977). Discipline and punish. Gamson \& Herzog.

Garfinkel, H. (1967). Studies in ethnomethodology. Prentice-Hall.

Geertz, C. (1973). The interpretation of cultures: Selected essays (pp. 3-30). Basic Books.

Gram-Hanssen, K. (2014). New needs for better understanding of household's energy consumption-behaviour, lifestyle or practices? Architectural Engineering and Design Management, 10(1-2), 91-107.

Heidegger, M. (1977). The question concerning technology and other essays. Harper \& Row.

http://mfkp.org/INRMM/article/13423553

Heidegger, M. (2001). Poetry Language Thought. Perennial Classics.

Herring, H. (2006). Energy efficiency-A critical view. Energy, 37(1), 10-20. https://doi.org/10.1016/j.energy.2004.04.055

Jackson, T. (2017). Prosperity without growth: Foundations for the economy of tomorrow (2nd ed). Routledge.

Johansen, J. P., Røyrvik, J., \& Gjøsund, G. (2019). What's the magic word? What we talk about when we talk about energy efficiency [Conference paper]. ECEEE Summer Study Proceedings 2019.

https://www.ecee.org/library/conference proceedings/ eceee Summer Studies/2019/1-the-dynamics-of-limiting-energyconsumption/whats-the-magic-word-what-we-talk-aboutwhen-we-talk-about-energy-efficiencyl

Jørgensen, U. (2012). Mapping and navigating transitions-The multilevel perspective compared with arenas of development. Research Policy, 47(6), 996-1010.

https://doi.org/10.1016/j.respol.2012.03.001

Kempton, W., \& Montgomery, L. (1982). Folk quantification of energy. Energy, $7(10), 817-827$.

https://doi.org/10.1016/0360-5442(82)90030-5

Larsen, T. (2010). Acts of entification: The emergence of thinghood in social life. In N. Rapport (Ed) Human nature as capacity: Transcending discourse and classification (pp. 154-178). Berghahn Books.

Latour, B. (1999). Pandora's hope: Essays on the reality of science studies. Harvard University Press.

Latour, B. (2005). Reassembling the social: An introduction to actornetwork theory. Oxford University Press.

Lutzenhiser, L. (2014). Through the energy efficiency looking glass. Energy Research \& Social Science, 1, 141-151.

https://doi.org/10.1016/j.erss.2014.03.011

Norwegian Ministry of Petroleum and Energy. (2016). Kraft til endring - Energipolitikken mot 2030 (Meld. St. 25 (2015-2016)) [Power for change - Energy policy towards 2030].

NVE. (2019). Kraftproduksjon. [Power production] https://www.nve.no/energiforsyning/kraftproduksjon/?ref= mainmenu
Oikonomou, V., Becchis, F., Steg, L., \& Russolillo, D. (2009). Energy saving and energy efficiency concepts for policy making. Energy Policy, 37(11), 4787-4796.

Patterson, M. G. (1996). What is energy efficiency?: Concepts, indicators and methodological issues. Energy Policy, 24(5), 377-390.

Ruzzenenti, F., \& Wagner, A. (2018). Efficiency and the rebound effect in the hegemonic discourse on energy. Nature and Culture, 13(3), 356-377.

Røyrvik, J., Olsen, M. S., \& Aasen, T. M. B. (2012). Political rationality and CCS discourse. Energy Procedia, 23, 284-295. https://doi.org/10.1016/j.egypro.2012.06.058

Sakai, M., Brockway, P. E., Barrett, J. R., \& Taylor, P. G. (2019). Thermodynamic efficiency gains and their role as a key 'engine of economic growth.' Energies, 12(1), 110.

Shove, E. (1998). Gaps, barriers and conceptual chasms: Theories of technology transfer and energy in buildings. Energy Policy, 26(15), $1105-1112$.

Shove, E. (2010). Beyond the ABC: Climate change policy and theories of social change. Environment and Planning A, 42(6), 1273-1285.

Shove, E. (2018). What is wrong with energy efficiency? Building Research \& Information, 46(7), 779-789. https://doi.org/10.1080/00613218.2017.1361746

Skjølsvold, T. M., Ryghaug, M., \& Dugstad, J. (2013). Building on Norway's energy goldmine: Policies for expertise, export, and market efficiencies. In E. Michalena \& J. M. Hills (Eds.), Renewable energy governance: Complexities and challenges. Springer, 337-349.

Solli, J. (2010). Where the eagles dare? Enacting resistance to wind farms through hybrid collectives. Environmental Politics, 19(7), 45-60.

Sorrell, S. (2015). Reducing energy demand: A review of issues, challenges and approaches. Renewable and Sustainable Energy Reviews, 47, 74-82.

Star, S. L. (2010). This is not a boundary object: Reflections on the origin of a concept. Science, Technology, \& Human Values, 35(5), 601-617.

Star, S. L., \& Griesemer, J. R. (1989). Institutional ecology, translations and boundary objects: Amateurs and professionals in Berkeley's Museum of Vertebrate Zoology, 1907-39. Social Studies of Science, 19(3), 387-420.

Steg, L. (2008). Promoting household energy conservation. Energy Policy, 36(12), 4449-4453.

https://doi.org/10.1016/j.enpol.2008.09.027

Svensson, A., \& Paramonova, S. (2017). An analytical model for identifying and addressing energy efficiency improvement opportunities in industrial production systems-Model development and testing experiences from Sweden. Journal of Cleaner Production, 142, 2407-2422.

The Federation of Norwegian Industries (Norsk Industri). (2016). The Norwegian process industries' roadmap: Combining growth and zero emissions by 2050.

https://www.norskindustri.no/siteassets/dokumenter/rapporterog-brosjyrer/veikart-for-prosessindustrien web.pdf

The Norwegian Society for the Conservation of Nature/Friends of the Earth Norway (Naturvernforbundet). (2018). Energieffektivisering. [Energy efficiency] https://naturvernforbundet.no/energi/energisparing/ 
The Research Council of Norway. (2018). Programrapport 2018 - Energi (ENERGIX, FME, CLIMIT).

Wei, T., \& Liu, Y. (2017). Estimation of global rebound effect caused by energy efficiency improvement. Energy Economics, 66, 27-34. https://doi.org/10.1016/j.eneco.2017.05.030

Wenger, E. (1998). Communities of practice. Cambridge University Press. Westskog, H., \& Winther, T. (2014). Electricity consumption: Should there be a limit? Implications of people's attitudes for the forming of sustainable energy policies. Consilience: The Journal of Sustainable Development, 11(1), 97-114.

Wilhite, H., \& Nørgård, J. S. (2004). Equating efficiency with reduction: A self-deception in energy policy. Energy \& Environment, 15(6), 991-1009.

https://doi.org/10.1260/0958305043026618 